\title{
Kontekstualizacija nekropolâ stećaka u teorijskoj arheologiji
}

EDITA VuČIĆ

Sveučilište u Mostaru

Fakultet prirodoslovno-matematičkih i

odgojnih znanosti

E-pošta: edita.vucic@fpmoz.sum.ba
UDK: 726.825

902.2

Izvorni znanstveni rad

Primljeno: 18. veljače 2019.

Prihvaćeno: 9. travnja 2019.

\section{Sažetak}

U radu se nastoji osvijestiti problem nedostatka teorijskih perspektiva u diskursima veznim za proučavanje stećaka. Rezimiraju li se dosadašnja proučavanja fenomena nekropolâ stećaka, evidentno je kako su ona na marginama znanstvenih disciplina poput arheologije, povijesti umjetnosti, povijesti, lingvistike i sl. Stoga se javlja potreba za kritičkim razmišljanjem na neke uvriježene i u znanosti ukorijenjene "zakonitosti". Kritičko promišljanje ne bi bilo moguće bez terenskog istraživanja autorice ovoga rada, te osvrta na teorijske perspektive u svjetskoj arheološkoj znanosti. Iste će se uzeti kao osnova za nove interpretacije i pokušaj inkorporiranja stećaka u suvremene arheološke tokove.

Ključne riječi: nekropole stećaka; tijek proučavanja; kritičko promišljanje; teorijska arheologija; nove interpretacije. 
Srednjovjekovni nadgrobni spomenici - stećci rasprostranjeni su na prostoru današnje Bosne i Hercegovine, Hrvatske (Dubrovačko i Makarsko primorje sa zaleđem, neki dijelovi Dalmatinskoga zagorja, dio Dalmacije do Zadra i dijelovi Like), zapadne Srbije (Podrinje i Polimlje) i SZ Crne Gore. Datiranje najstarijih bilješki o stećcima u Bosni seže u XVI. st., a tiču se putopisa Benedikta Kuripešića. Svijet je upoznao stećke s područja Dalmacije i $\mathrm{BiH}$ tek u drugoj polovici XVIII. st., zahvaljujući A. Fortisu. Predmetom multidisciplinarnih istraživanja domaćih i inozemnih stručnjaka stećci postaju tek krajem XIX. st., ${ }^{1}$ dok njihovo sustavno istraživanje započinje nakon austro-ugarske okupacije i utemeljenja Zemaljskoga muzeja u Sarajevu $1888 .^{2}$ Do 1945. godine istraživanje stećaka temeljilo se u velikoj mjeri na proučavanju natpisa. Izložba jugoslavenskoga srednjovjekovnog slikarstva i plastike održana u Parizu 1950. rezultirala je povećanjem interesa i objektivnijem znanstvenom pristupu. Konferencije održane u Sarajevu 1950. i 1952. godine najviše su doprinijele planskoj i organiziranoj zaštiti spomenika kulture. Sve dobivene podatke analizirali su stručnjaci. Do 1980. godine dobio se približno točan broj danas poznatih spomenika, njih 69.356 na više od 3162 nekropole, ali se pretpostavlja da ima onih koji još uvijek nisu otkriveni. ${ }^{3}$

Rezimiramo li dosadašnja proučavanja fenomena ${ }^{4}$ nekropolâ stećaka, evidentno je kako su za njihovo interpretiranje nedovolj-

1 Istaknut ćemo neke značajne osobe XIX. st.: Aleksandar Sapieha, Ami Boue, Arthur Evans, Andrija Kačić Miošić, Ivan Cerrara, Lovre Katić, fra Petar Bakula, i dr.

2 Imena koja se vezuju za izučavanje stećaka tijekom XX. st. jesu: Moritz Hoernes, Janos Asboth, Konstantin Jireček, Luko Zore, Vid Vuletić Vukasović, Lujo Marun, Kosta Horman, Ćiro Truhelka, Stjepan Gunjača, Đuro Basler, Alojz Benac, Nada Miletić, Jaroslav Šidak, Aleksandar Solovjev, Pavao Anđelić, Marian Wenzel koja je za doktorsku disertaciju obradila ukrasne motive na stećcima i najveće ime stećkologije Šefik Bešlagić kojemu je 2014. godine bio posvećen prvi Međunarodni znanstveni skup o stećcima održan u Sarajevu.

3 ŠEFIK BeŠLAGić, Leksikon stećaka, Svjetlost, Sarajevo, 2004., str. 179.

4 Termin fenomen koristi se u svojstvu opisa stećaka u kontekstu njihove brojnosti, raznovrsnosti oblika, repertoara reljefnih motiva, natpisa i dr. Atribut je naglašen u UNESCO-ovom Nominacijskom dosjeu u kojemu su stećci izdvojeni iz cjelokupnoga konteksta europske sepulkralne prakse: Criterion (iii) Although immersed in medieval European culture and the historic context and specificity of the area where we find them, with traces of earlier influences (prehistoric, antic and early medieval), stećci, by several aspects, remain a unique phenomenon in European medieval artistic and archaeological heritage. The 
ne pojedinačne discipline kao što su arheologija, povijest, povijest umjetnosti, religija i književnost, te kako istraživanje mora biti interdisciplinarno. Zanemaren je i arheološki kontekst, točnije analize nalaza ukoliko ih je bilo u grobovima, te osteološkoga i dentalnoga materijala individua pokopanih pod stećcima. ${ }^{5}$ Obrada kasnosrednjovjekovnih nekropolâ stećaka uglavnom se svodila na kronološka i tipološka razmatranja nadgrobnih spomenika, te interpretiranje ikonografije oko koje se još uvijek vode rasprave sagledavajući je kroz prizmu modernih događanja i percepciju promatrača XXI. stoljeća. Sumiranjem objavljenih izvora i literature primjećuje se subjektivnost autora i ideološki utjecaji vremena u kojemu su objavljivali svoje radove. Proučavanje stećaka aktualizirano je nakon pokretanja procesa nominacije na UNESCO-ov Popis svjetske baštine 2009. godine. U tom razdoblju oživjele su neke stare teze o podrijetlu stećaka, ali i oblikovane različite paradigme nerijetko utemeljene na okolnostima dnevnopolitičke naravi, etno-nacionalnim konceptima ili religijskim uvjerenjima. Najbolji je primjer bogumilska teza s kraja XIX. st., zatim teza o heretičkoj Crkvi bosanskoj, te nastojanja kroatizacije, srbizacije i bošnjakizacije stećaka. ${ }^{6}$ Uzrok treba tražiti u nedovoljno

main specificity is exactly the number not been recorded anywhere else in Europe - about 70000 documented and recorded monuments! Furthermore, the distinct characteristic is the diversity of forms. Today we know the following basic forms: slabs, chests, gabled roof tombstones, pillars, monumental crosses... Their reliefs are an exceptional testimony of medieval culture which has disappeared and of which stećci are often the only traces. The reason for this is in an unbelievable richness of reliefs of various content - images of everyday life, symbolic and religious depictions and decorative details. The emergence of various inscriptions further contributes to their specificity given that these are extraordinary monuments of medieval literacy, which spread to almost all social ranks and nowadays have a multiple function - from being historical source to the study of different cultural and social influences. https://whc.unesco.org/ uploads/nominations/1504.pdf (10. 2. 2019.).

5 Od sustavno istraženih nekropola i pojedinačnih grobova tijekom XX. st. treba istaknuti nekropole Grborezi, Biskup kod Konjica, te onu na vrelu rijeke Cetine, koja danas broji oko 700 stećaka.

6 Plasiranje bogumilske teze o karakteru Crkve bosanske F. Račkoga i A. Evansa u XIX. st. pod utjecajem je buđenja nacionalne svijesti tijekom toga razdoblja. Posljednji je rat ponovo pobudio jačanje nacionalnoga identiteta, što je utjecalo na oživljavanje bogumilske teze u radovima arheologa i povjesničara E. Imamovića te povjesničara I. Pašića. Pravoslavni karakter Crkve bosanske i srpski karakter stećaka isticali su Ć. Truhelka, V. Glušac i B. Petranović, dok su na hrvatskoj strani I. Pilar, D. Mandić i F. Šanjek zastupali hrvatski karak- 
jasnom definiranju problema i metodološkoga pristupa, koji nemaju jasno postavljen ili izgrađen teorijski okvir za donošenje konačnoga arheološkog zaključka. Iako arheologija na "Zapadu"7 podrazumijeva uzajamno prožimanje teorije i prakse, dosadašnji arheološki pristupi izučavanju nekropola stećaka nemaju osnove u teorijskim načelima koji će biti prezentirani u daljem izlaganju. Naglasak u istraživanju treba biti na prožimanju antropologije koja donosi teoriju iz današnjega društva, etnologije koja proučava nematerijalnu dimenziju stećka, povijesti koja proučava pisane izvore i na arheologiju koja daje sliku stvarnoga stanja na terenu.

U nedostatku pisanih vrela i rezultata arheoloških istraživanja grobnih cjelina javlja se potreba za interdisciplinarnim pristupom i kritičkim promišljanjem o nekim uvriježenim i u znanosti ukorijenjenim "zakonitostima". Stoga će kratki osvrt na teorijske perspektive u svjetskoj arheološkoj znanosti biti temelj novoga interpretativnog okvira i pokušaja inkorporiranja stećaka u suvremene teorijske pristupe. Arheologija u zapadnoj Europi, a i šire, svoje interpretacije nominalno temelji na rezultatima arheoloških istraživanja i teorijskih pristupa pod čime se podrazumijeva podjela na kulturno-historijsku, procesnu ili novu te postprocesnu arheologiju. Za sada su teorijski pristupi mnogo više zastupljeni u izučavanju prapovijesti i antičkoga doba nego u kasnosrednjovjekovnoj arheologiji. Sukladno suvremenim znanstvenim standardima empirijski podatci, dobiveni arheološkim istraživanjima, moraju biti popraćeni teorijskim udjelom u konačnu interpretaciju.

Bosanskohercegovačka, pa i hrvatska arheološka znanost, fokusirane su na arheološka istraživanja i empirijske podatke na temelju kojih daju konačnu interpretaciju prošlosti (kulturno-povijesna arheologija). ${ }^{8}$ Kulturno-povijesna arheologija izrazito je empirijska disciplina, što znači da svoje zaključke nominalno temelji isključivo na empi-

ter stećaka. Problem današnje historiografije jest inkorporiranje suvremenih konstrukata u povijesnu prošlost i pokušaj definiranja stećaka sukladno prisutnim etno-nacionalnim tendencijama.

7 Zapad nije uniformirano područje i tamo se prakticiraju razni teorijski pravci. Zapad je sociološki konstrukt, a sam termin će se zbog preglednosti teksta koristiti u radu.

8 Igor Kulenović, Materijalna kultura, značenje i praksa, Naklada Slap, Jastrebarsko, 2013.; RAJNA ŠošIĆ-KLINDŽIć, Uvod u teorijsku arheologiju - stvaraoci i pravci u XX. st., FF press, Zagreb, 2015.; BJonAR Olsen, Od predmeta do teksta; Teorijske perspektive arheoloških istraživanja, Geopoetika, Beograd, 2002. 


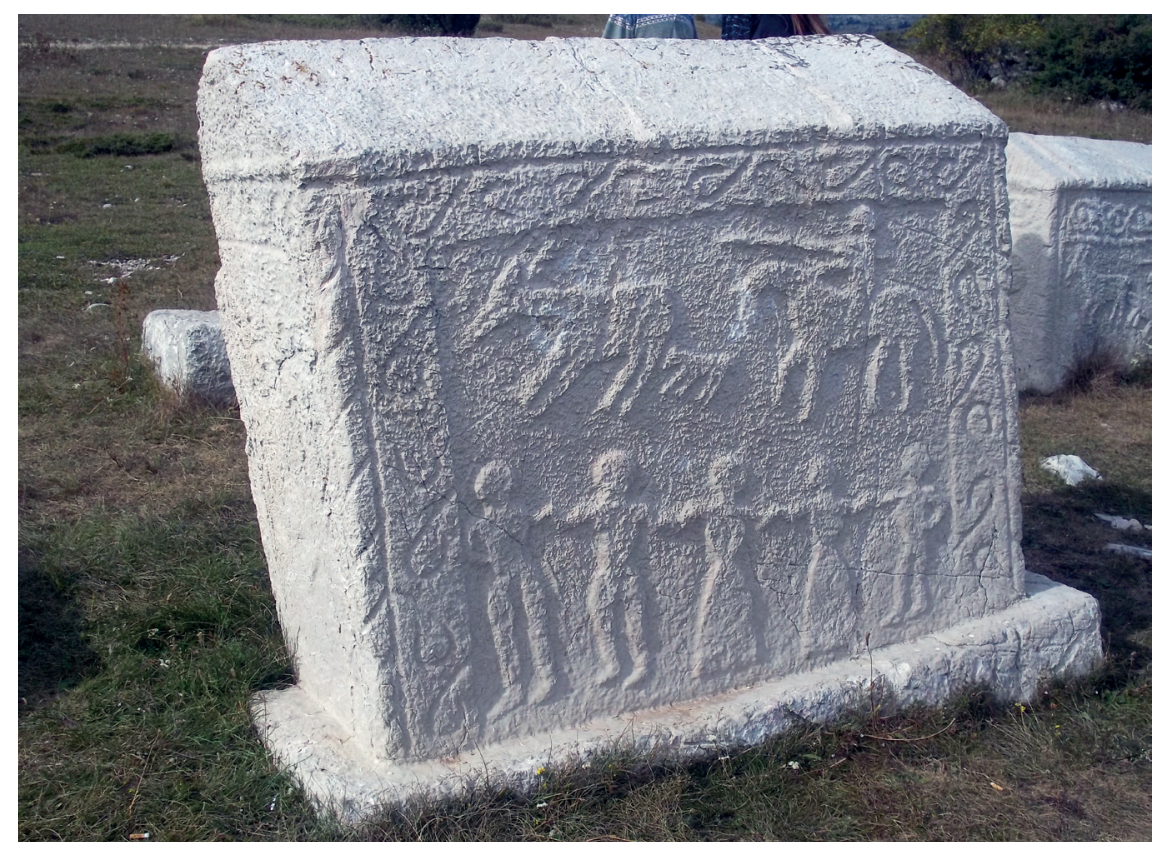

Sl. 1. Sljemenjak s nekropole Dugo polje

rijskim podatcima i raspoređivanju arheološke građe $\mathrm{u}$ razdoblja stvaranjem kronološko-tipoloških okvira. ${ }^{9} \mathrm{Na}$ tragu rečenoga, u razdoblju pionirskih proučavanja stećaka s kraja XIX. st. prepoznaje se kulturno-povijesni obrazac kojim je obuhvaćena obrada empirijskih podataka utemeljena na kronološko-tipološkim odlikama stećaka, brojnom stanju na nekropolama i pokušaju organizacije motiva u određene skupine.

Svako odstupanje u odabiru motiva ili oblika nadgrobnih spomenika objašnjavalo se kroz različite identitete individua pokopanih ispod

9 Arheologiju XIX. stoljeća obilježila su imena poput Thomsena, Worsaaea i Monteliusa, te sustavno raspoređivanje arheološke građe u određena razdoblja. U razdoblju od 1890. do 1900. i 1960. godine, arheologija na Zapadu naziva se kulturno-povijesnom, tradicionalnom ili normativnom arheologijom. Krajem XIX. st. u arheologiju se uvodi pojam arheološke kulture koja je definirana na temelju sličnosti i materijalnoj kulturi i načinu života, a to je bilo moguće samo ukoliko postoji etničko jedinstvo. Kulture su nazvane po mjestu pronalaska ili prepoznatljivoj arheološkoj građi. Izvorom promjena smatrane su migracije i difuzija što je u osnovi imalo načelo evolucionističke arheologije XIX. stoljeća. B. OlsEN, Od predmeta do teksta, str. 32-35; R. Šošić-KLINDŽIĆ, Uvod u teorijsku arheologiju - stvaraoci i pravci u XX. st., str. 89. 
stećaka. Oblike stećaka brojni su autori smještali u kronološke faze, a kao kriterije uzimali su razvoj bosanske države ${ }^{10}$ i pojavu Vlaha na srednjovjekovnoj sceni, pri čemu su stećke oblika sljemenjaka isključivo interpretirali kao Vlaške (Benac, Wenzel, Milošević). Š. Bešlagić napravio je opće prihvaćenu sintezu i podjelu stećaka definirajući ih po obliku, dok je M. Wenzel obradila umjetničke motive smještajući ih u određene kontekste i okvire, što je svakako bila velika prekretnica u njihovu izučavanju (Sl. 1). Evidentno je kako kulturno-povijesni model nije dostatan da bi se u potpunosti predočila kultura izrade stećaka, okolnosti nastanka takvoga običaja pokapanja i njegov razvoj tijekom stoljeća.

Novo poglavlje u povijesti arheološke znanosti, poznato pod terminom nova ili procesna arheologija, ${ }^{11}$ započelo je 60 -ih godina XX. st., kad se arheološko središte iz Europe premjestilo u SAD. ${ }^{12} \mathrm{U}$ istom je razdoblju došlo do razvoja metode radiokarbonskoga datiranja i prirodnih znanosti, računalne tehnologije, nove biologije, primjene matematike i statistike, povećane brige za okoliš, izmjenâ i dopunâ zakonâ o građanskoj jednakosti, što je utjecalo i na nastanak nove arheologije. ${ }^{13}$ Nova je arheologija pod utjecajem razvoja prirodnih znanosti težila objektivnosti i provjerljivosti arheološkoga zaključka.

10 Pojavu stećka kao oblika monumentalne arhitekture Benac i Bešlagić povezuju sa širenjem državnoga teritorija pod vlašću bana Stjepana II., jačanjem trgovačkih veza s mediteranskim zemljama i razvojem rudarstva, te društvenim raslojavanjem od sredine XIV. st. (Alojz BENAC, Radimlja, Srednjevjekovni nadgrobni spomenici Bosne i Hercegovine, I., Zemaljski muzej, Sarajevo, 1950.; ŠEfIK BeŠLAgIĆ, Stećci i njihova umjetnost, Zavod za izdavanje udžbenika, Sarajevo, 1971.)

11 Lewis Binford je ime koje se vezuje uz nastanak nove ili procesne arheologije. Smatrao je kako arheolozi mogu proučavati iste probleme kao antropolozi. $\mathrm{Na}$ temelju analize arheološke građe bilo je moguće dobiti podatke o svim aspektima društva, koje je analizirano kao jedan sustav sa svojim podsustavima. Procesnu arheologiju obilježile su logičkopozitivistička teorija znanja i funkcionalističko poimanje društva i kulture. B. OlsEN, Od predmeta do teksta, str. 44-45.

12 Arheologija je u Europi bila vezana uz povijesnu znanost (David L. Clarke), dok je u SAD-u promatrana kao dio antropologije (Lewis Binford). U svojoj knjizi The idea of history, britanski arheolog, povjesničar i filozof R. Collingwood opisuje povijest kao povijest ljudskoga uma. Povijesne podatke smatrao je građom koja se samo kroza smisao povjesničara može pretvoriti u povijest. R. Šošıć-KLINDžIć, Uvod u teorijsku arheologiju - stvaraoci i pravci u XX. st., str. 25.

13 Isto, str. 93. 
Naziv procesna dobila je zbog toga što kritizira isključivu usmjerenost na predmete, ustrajavajući na konceptu dinamičkih procesa, kao i na definiranju jasne metodologije i kriterija za njihovo proučavanje. Što se tiče ekonomskoga i kulturnoga razvoja društva, on se promatra u kontekstu ekoloških i funkcionalnih aspekata. ${ }^{14}$

Kontekstualizirajući teze Š. Bešlagića prepoznajemo ekološko-funkcionalni stav u pogledu odabira mjesta za nastanak nekropole koji je, prema njegovim riječima, zavisio od blizine kamenoloma, naselja i konfiguracije terena. ${ }^{15}$ Funkcionalističko shvaćanje materijalne kulture reflektira se u objašnjenjima da su nekropole iz praktičnih razloga i zahtjevnoga transportiranja kamenih blokova vjerojatno formirane u blizini kamenoloma. Za obradu kamena korištene su različite vrste alata, ali sam je proces ovisio ne samo o vještini majstora i kvaliteti alatki, nego i o vrsti i kakvoći kamena. ${ }^{16}$

Iako se u početcima razvoja nove arheologije vjerovalo kako u društvu i kulturi moraju postojati određene zakonitosti, s vremenom dolazi do promjena u shvaćanjima procesnih arheologa zbog manjkavosti znanstvenih metoda i nemogućnosti svođenja istraživanja pod zajednički nazivnik. ${ }^{17} \mathrm{Za}$ razvoj procesnoga pristupa u Engleskoj zaslužni su D. Clarke i C. Renfrew. Clarke je poput Binforda koristio "teoriju sustava"18 da bi objasnio promjene koje se događaju unutar

14 Društvo i kultura shvaćeni su kao funkcionalni sustav kojim upravlja unutarnja logika - različiti dijelovi sustava moraju biti u međusobnoj harmoniji, a sustav kao cjelina u ravnoteži s prirodnim okolišem. R. Šošıć-KLINDžIć, Uvod u teorijsku arheologiju - stvaraoci i pravci u XX. st., str. 104; B. OlsEN, Od predmeta do teksta, str. 43-44.

15 ŠEFIK BeŠLagić, Stećci - kultura i umjetnost, Veselin Masleša, Sarajevo, 1982. str. 37-40.

16 Za klesanje su najčešće korišteni krečnjak, miljevina, jablanit, plivit, konglomerat i sl.

17 Binford tako uviđa nemogućnost "dobivanja podataka o nekad živoj zajednici na temelju mrtve i statične građe", čime je naglasio problematiku proučavanja prošlosti i sadašnjosti. Mogućim rješenjem smatrao je uspostavljanje međuodnosa između materijalne kulture, $\mathrm{tj}$. arheološke građe i društvenoga ponašanja. B. OlsEn, Od predmeta do teksta, str. 50.

18 Teorija sustava utemeljena je na premisama biologa Ludwiga von Bertalanffyja koji je tvrdio kako svim sustavima sastavljenim od međuzavisnih i povezanih podsustava upravljaju univerzalne zakonitosti, neovisno o funkciji svakoga pojedinačnoga sustava. U arheologiju je ušla preko antropologije, ali u potpunosti nije primjenjiva zbog toga što teži potpunoj zatvorenosti sustava, što otežava izradu modela društva. B. Olsen, Od predmeta do teksta, str. 130. 
Edita Vučić - Kontekstualizacija nekropolâ stećaka u teorijskoj arheologiji

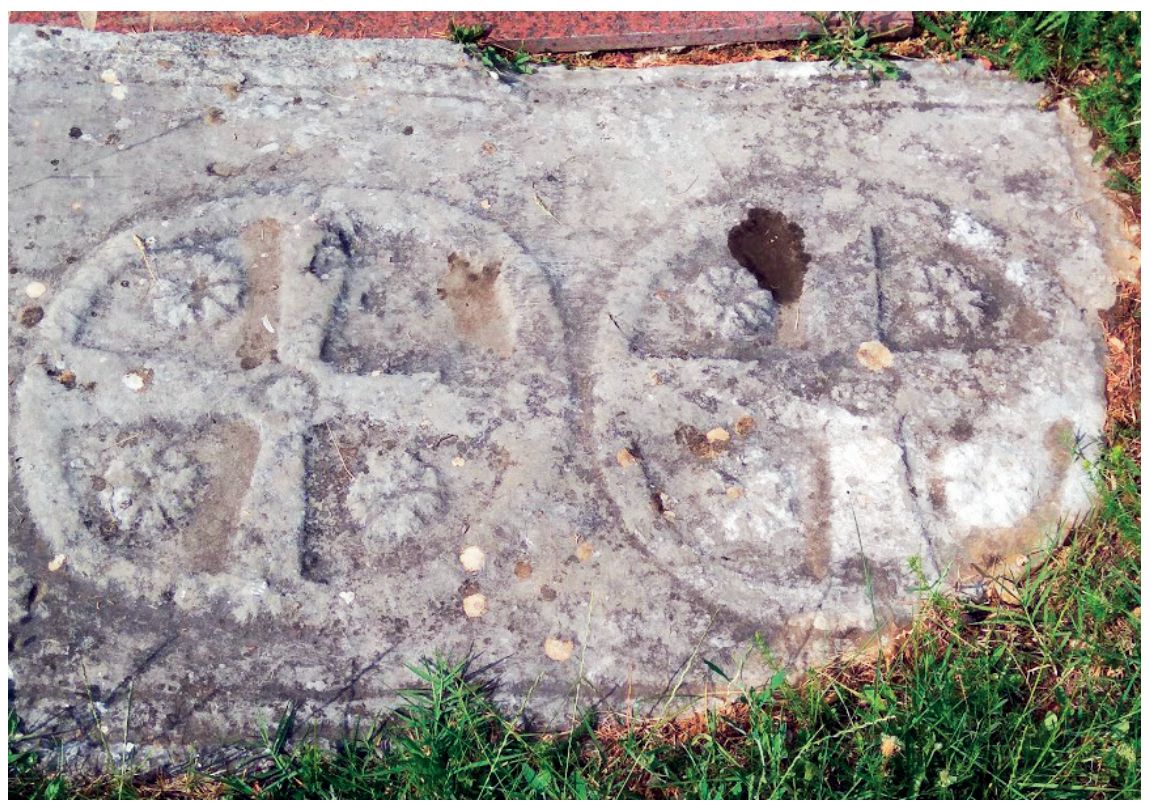

S1. 2. Motivi na stećku, Dobro Selo

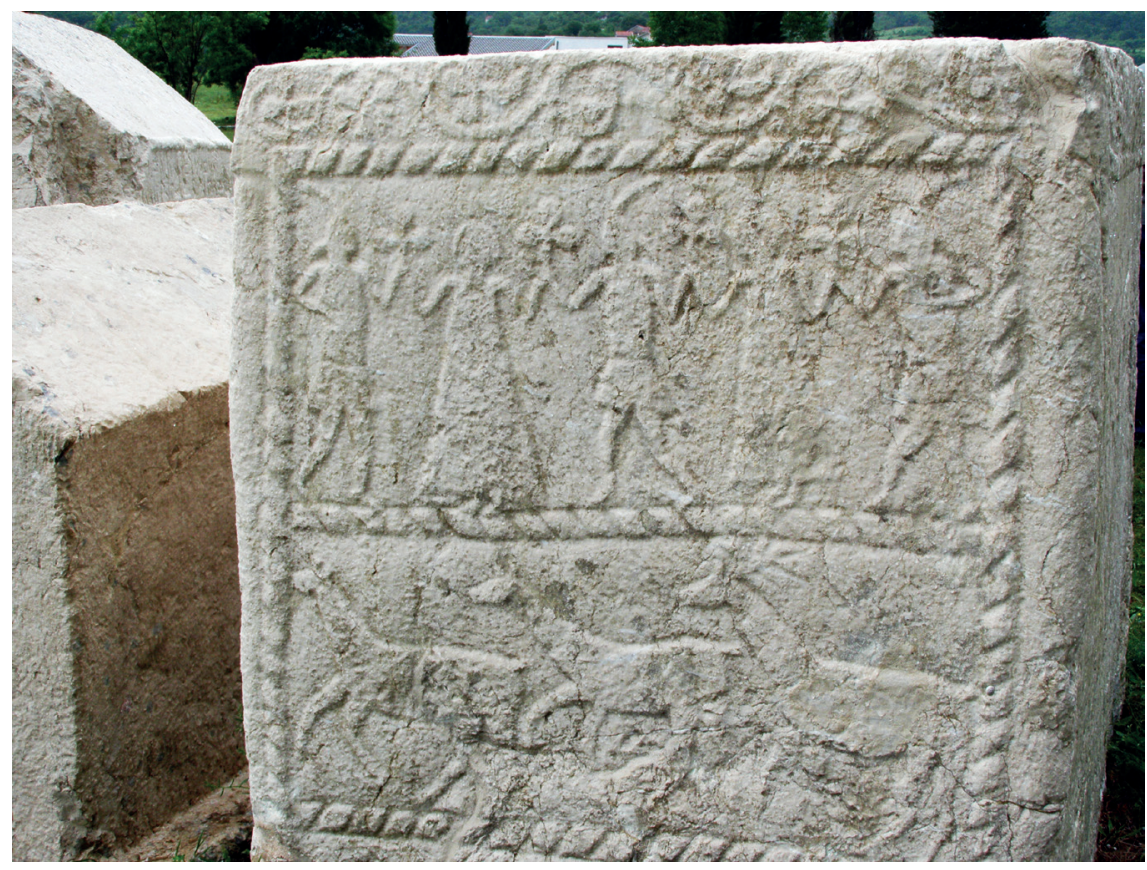

Sl. 3. Detalj stećka s nekropole Radimlja 


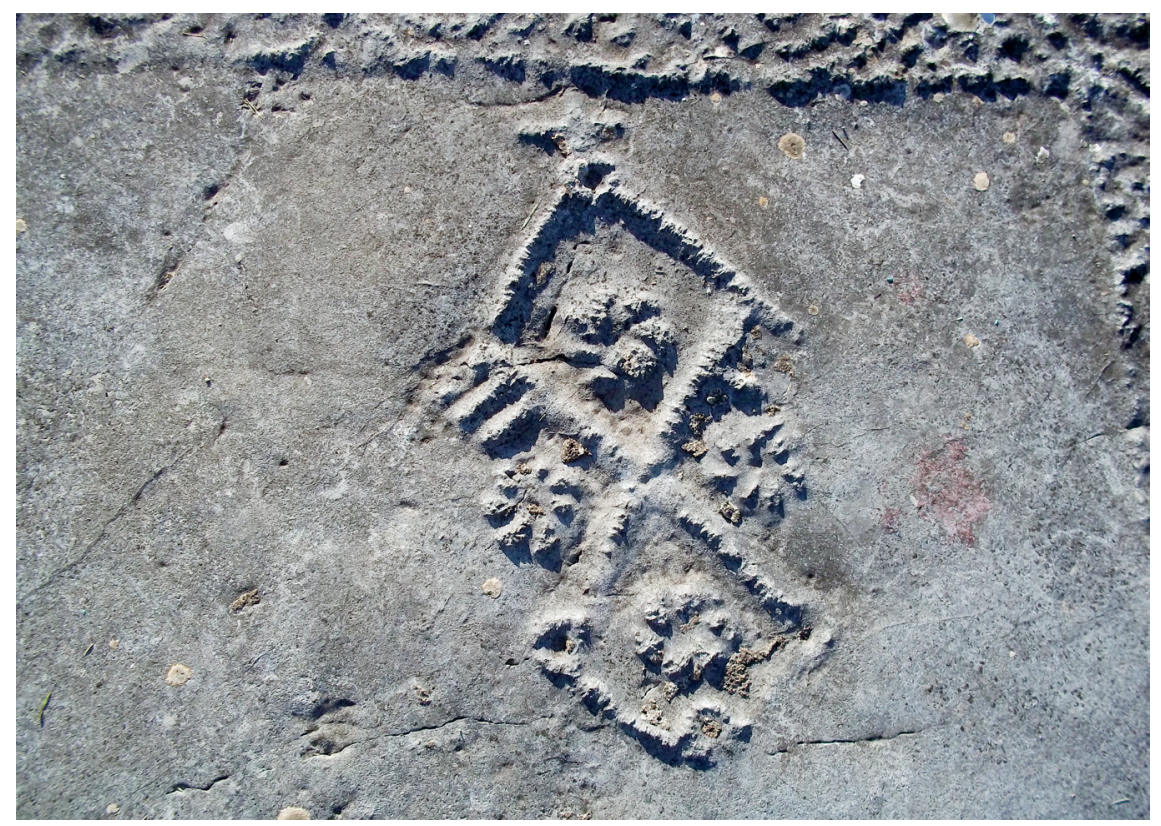

Sl. 4. Detalj na stećku s nekropole Ledinac

društva. Kulturne promjene unutar društva nastojao je objasniti u kontekstu prilagodbi na nove okolnosti.

Kulturni razvoj srednjovjekovne bosanske države i ekonomske promjene uvjetovane razvojem trgovine i kontakta s drugim populacijama, najčešći su argumenti za pronalazak analogija s umjetnošću europskoga istoka i zapada. Upravo se difuzionističko stajalište ${ }^{19} \mathrm{o}$ širenju ideja i umjetničkih utjecaja iz europskih centara, koje su potaknule kulturnu promjenu, ogleda u riječima P. Anđelića koji kaže kako je geografski smještaj Bosne i Hercegovine između kulturnih sfera Istoka i Zapada odredio njezinu kulturnu fizionomiju. ${ }^{20}$ Čini se

19 Pojam difuzije u kulturno-povijesnoj arheologiji odnosi se na utjecaje, utok ideja i kulturne pozajmice. Promjene se objašnjavaju kao kulturne pozajmice i širenje ideja preko kontakata. B. Olsen, Od predmeta do teksta, str. 117.

20 Anđelić navodi sljedeće: "U bosanskoj historiji bilo je sukoba i međusobne penetracije i slabljenja uticaja Istoka i Zapada, ali se ovdje snažno i neočekivano za ovako mali prostor pojavila još jedna reakcija: u konstelaciji sukoba, međusobnoga prožimanja i slabljenja elemenata istočne i zapadne kulture, došlo je do pojave još jedne komponente - stvaranja novih, originalnih, vlastitih kulturnih kvaliteta". PAVAO AnĐElić, "Doba srednjovjekovne bosanske države", 
da je N. Miletić ostala dosljednoga stava o složenom podrijetlu motiva i neiscrpnim mogućnostima interpretiranja, čime nije izostavila utjecaje najstarijih vidova čovjekova likovnog izražavanja ${ }^{21}$ (Sl. 2, 3 i 4).

U razdoblju eksploatacije rudnih bogatstava i intenziviranja trgovine između srednjovjekovne bosanske države, europskih središta i mediteranskoga svijeta, došlo je do jednoga oblika socijalne revolucije. Srednjovjekovno je društvo prolazilo kroz promjene koje su uvjetovale izraženije raslojavanje na feudalnu vlastelu, svećenstvo, trgovce i obični puk. Trgovina je omogućila kontakte i razmjenu ideja sa susjednim državama i šire, što se najviše odrazilo na jačanje gradskih centara i implementiranje dvorskoga života. Niži društveni slojevi nisu bili isključeni iz navedenih procesa, ali na njih su utjecali u znatno manjoj mjeri. ${ }^{22}$ Promjene su se manifestirale zahvaljujući međusobnim prožimanjima utjecaja koji su dolazili iz raznih europskih smjerova i kombinacija autohtonih umjetničkih elemenata. Razvoj kulture i umjetnosti izražen je u knjižnom slikarstvu, iluminiranim rukopisima, i najvrjednijem što danas baštinimo - epigrafskoj i reljefnoj građi na nadgrobnim spomenicima.

Potrebno je istaknuti kako su u periodu razvoja procesnoga pristupa u Bosni i Hercegovini nastale dvije važne publikacije Stećci, kataloško-topografski pregled Šefika Bešlagića i Ukrasni motivi na stećcima Marian Wenzel. Krajem 80-ih publiciran je Arheološki leksikon Bosne $i$ Hercegovine u pet svezaka, popraćen mapama svih evidentiranih Regija na kojima su zabilježeni arheološki lokaliteti iz prapovijesti, antike i srednjega vijeka. Na jednom su nalazištu evidentirani materijalni tragovi iz više arheoloških razdoblja, što je dokaz kontinuiteta

u: Kulturna istorija Bosne i Hercegovine od najstarijih vremena do pada ovih zemalja pod osmansku vlast, Drugo prerađeno i dopunjeno izdanje, Biblioteka Kulturno nasljeđe, Veselin Masleša, Sarajevo, 1984., str. 439; DubRavko LoVRENOVIĆ, Stećci, bosansko i humsko mramorje srednjeg vijeka - monografija, Rabic, Sarajevo, 2009.

21 Nada Miletić, Stećci, Umetnost na tlu Jugoslavije, Beograd - Zagreb - Mostar, 1982., str. 97-100.

22 Najstariji podatci o razvoju trgovine s Dubrovčanima datiraju u period vladavine bana Kulina. Pripajanjem Humske zemlje Bosanskoj banovini u trećem desetljeću XIV. st., intenziviraju se trgovačke veze i s drugim primorskim gradovima. Najvažniji put via Narenti išao je od Dubrovnika preko Stona do Drijeva, prema Bišću ispod Blagaja, te Konjica i Ivan-planine u Bosnu. Put koji je išao dolinom Drine via Drine, vodio je iz Dubrovnika prema Srbiji i Carigradu (Split, Trogir, Šibenik). Emir Filipović, Bosansko kraljevstvo, Historija srednjovjekovne Bosanske države, Mladinska knjiga, Sarajevo, 2017., str. 603-604. 
ukapanja na većini lokaliteta. U kontekstu takva istraživanja nastale su hercegovačka (pet klesarskih radionica) i bosanska klesarska škola (radionice u zapadnoj, srednjoj i istočnoj Bosni), od kojih svaka pojedinačno ima svoje centre sa specifičnim likovnim obilježjima. ${ }^{23}$

Krajem 70-ih dolazi do novih strujanja u arheološkoj znanosti poznatih pod nazivom postprocesna arheologija. Postalo je evidentno da se arheologija ne može poistovjećivati s prirodnim znanostima ili pak ponuditi objektivne i mjerljive rezultate, te da u istraživanju nedostaju duhovni aspekt i pojedinac kao aktivni sudionik u proučavanju kulturnoga konteksta. ${ }^{24}$ U Velikoj Britaniji se početkom 1980 ih publiciraju prvi radovi kojima se kritiziraju stajališta procesne arheologije, uvodeći potpuno nove pristupe koji su se temeljili na antropologiji, filozofiji, feminizmu, marksizmu i kognitivnoj znanosti. Osnovna odlika postprocesnoga pristupa u arheologiji upravo je heterogenost kojom je obuhvaćeno više pravaca utemeljenih na francuskom strukturalizmu, poststrukturalizmu, marksizmu, feminističkoj teoriji, hermeneutici i kritičkoj teoriji. ${ }^{25}$ Zauzet je potpuno novi stav prema kojemu su članovi društva glavni akteri u oblikovanju svoje društvene zbilje, a iznimno je kritizirana teza o čovjekovu prilagođavanju okolišu. ${ }^{26}$ Težište arheoloških rasprava, čiji je začetnik britanski arheolog I. Hodder, ${ }^{27}$ ponovo se iz SAD-a vraća u Europu. ${ }^{28}$

23 Š. BeŠLAgić, Stećci - kultura i umjetnost, str. 467-468; Leksikon stećaka, str. 174; N. Miletić, Stećci, str. 109-116; Alojz Benac, Stećci, Izdavački zavod "Jugoslavija", Beograd, 1967., str. 8.

24 R. ŠošIĆ-KLINDžIć, Uvod u teorijsku arheologiju - stvaraoci i pravci u XX. st., str. 117-118.

25 B. Olsen, Od predmeta do teksta, str. 57.

26 Postprocesna arheologija stavlja težište na simboličke i komunikativne aspekte materijalne kulture te ističe važnost arheologije kao humanističke discipline, kritizirajući pri tome njezino funkcionalističko viđenje i nastojanje procesne arheologije da postigne apsolutnu istinu. B. OlsEN, Od predmeta do teksta, str. 58.

27 Godine 1982. objavljene su dvije knjige Iana Hoddera, Symbols in action i The present past, te zbornik radova Symbolic and structural archaeology.

28 IAN Hodder, Symbols in action - Etnoarchaeological studies of material culture, Cambridge University press, Cambridge, 1982.; IAN HodDER, The present past, Batsford, London, 1982., Cambridge University Press, Cambridge, 1982.; Mathew Johnson, Arheological theory: An introduction, Wiley-Blackwell, 1999., str. 101-104; RoberTa GILCHRIST, "Medieval archaeology and theory: a disciplinary leap of faith", u: R. Gilchrist - A. Reynolds, Reflections: 50 years of Medieval archaeology, 1957 - 2007., Society for medieval archaeology monographs, Maney, Leads, 2007., str. 385-408. 
S ciljem boljega razumijevanja kulturnoga i društvenoga ponašanja Hodder uvodi pojmove strukture i strukturalizma, ali pristup nije naišao na pozitivne reakcije $u$ teorijskoj arheologiji. ${ }^{29}$ Zagovarao je i stav da se važnost materijalne kulture, točnije odnos između ljudi, njihova djelovanja i materijalne kulture, mogu razumjeti samo ukoliko se proučava kulturno-povijesni kontekst. ${ }^{30}$

Izučavanje nekropola stećaka nedvojbeno treba staviti u kulturnopovijesni kontekst, a pogrebni ritual razmatrati kao heterogen, a ne normativan proces. Treba imati na umu kako umjetnost toga doba nije slična našemu konceptu, niti su umjetnici slijepo slijedili onovremene europske kanone. Kontekst izučavanja trebao bi ovisiti ne samo o povijesnom okviru, nego i o drugim parametrima koji se odnose na sudionike $\mathrm{u}$ procesu izrade nadgrobnoga spomenika te na uvjete u kojima se odvijao ukop pokojnika.

Razmatranjem vjerskih prilika u srednjovjekovnoj Bosni uvriježeno je mišljenje kako je čovjek srednjega vijeka pridavao veliku važnost ulozi religije u svakodnevnome životu, neovisno o svom društvenom i socijalnom statusu. Evidentno je to iz vjerske opredijeljenosti bosanskih vladara i vlastele koja je lavirala između vjere Crkve bosanske, pravoslavlja i katoličanstva. Vjera je prožimala sve kulturne identitete i na određeni način izjednačavala sve članove zajednice. ${ }^{31}$

U postojećoj literaturi, vezanoj za predmetni diskurs, dominiraju mišljenja kako je vlastela, koja je imala monopol nad kamenolomima i radnom snagom, jedina mogla priuštiti klesanje i obradu kamena. Bešlagić je pretpostavio moguću poveznicu između izdvojenih skupi-

29 Strukturalizam je (teorija o kulturi) posuđen iz lingvistike. Njime se nastoji pokazati kako materijalna kultura nastaje u skladu s jezičnim gramatičkim pravilima. Hodder je dao definiciju strukture smatrajući da su to pravila prema kojima se odvijaju odnosi koje zapažamo u arheološkom materijalu, ali ovako postavljena struktura ne objašnjava društvenu praksu i kulturnu promjenu. Kod strukturalizma oblik i praksa izdvojeni su kao i kod funkcionalizma. Kao takav, strukturalizam nije zaživio u arheologiji. I. Kulenović, Materijalna kultura, značenje i praksa, str. 48-50; B. OlsEN, Od predmeta do teksta, str. 179-180.

30 I. HodDER, Symbols in Action - Etnoarchaeological studies of material culture, str. 202-205; B. OlsEN, Od predmeta do teksta, str. 62, 95.

31 Veliki je ugled uživalo svećenstvo koje se nakon uspona latinskoga kršćanstva i jačanja rimskoga pape početkom IX. st. nametnulo i u sferama društvenoga i političkoga života. E. FILIPović, Bosansko kraljevstvo, Historija srednjovjekovne Bosanske države, str. 537. 


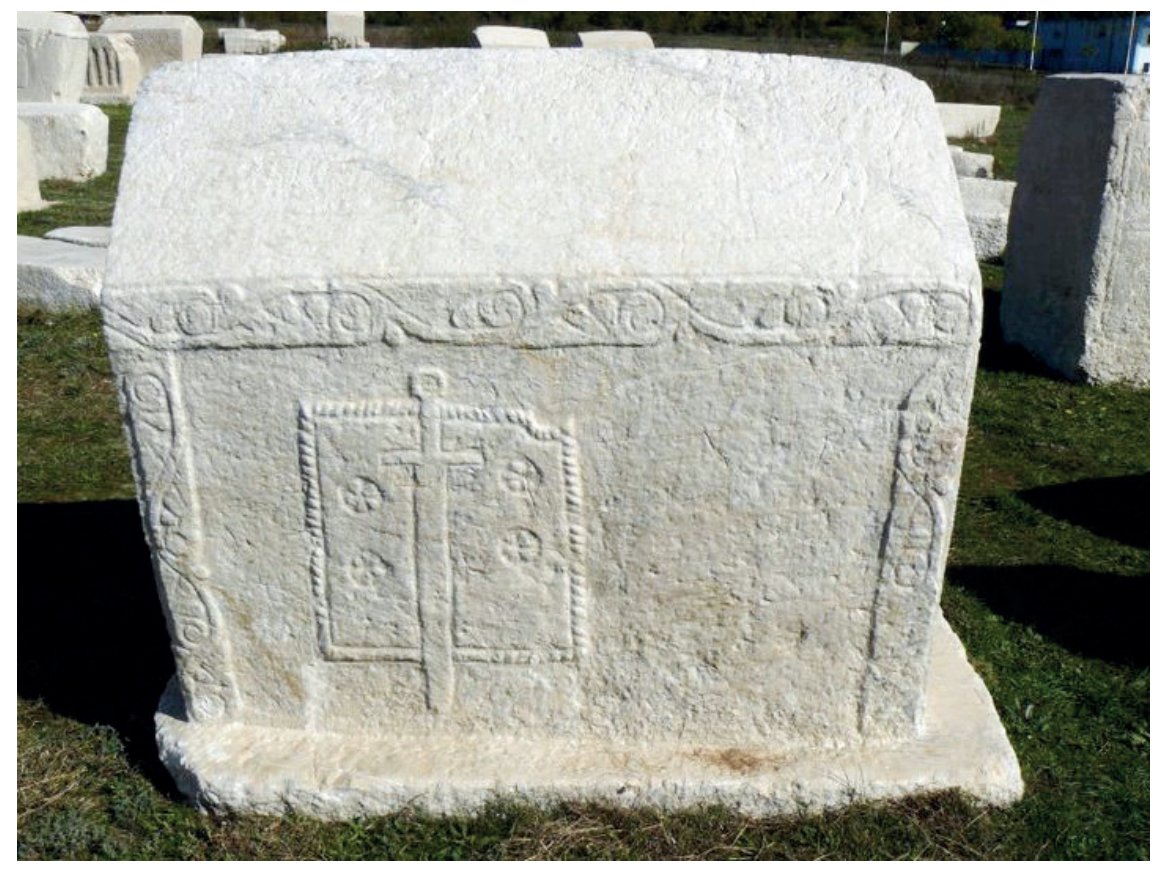

S1. 5. Stećak na nekropoli Radimlja

na stećaka i socijalnoga statusa. Mišljenja je kako su manje grupacije stećaka posljedica društvenoga raslojavanja i težnje za formiranjem obiteljskih grobalja na svojoj baštini. ${ }^{32}$ Dio toga državnog ekonomskog sustava bili su i vlaški katuni. Vlasi su u historiografiji različito tretirani, a pitanje njihova podrijetla još je uvijek diskutabilno i neusuglašeno ${ }^{33}(\mathrm{Sl} .5)$.

U nedostatku pisanih izvora nameće se nekoliko pretpostavki i pitanja o tome jesu li isključivo bogatiji slojevi društva koristili oblike nadgrobnih spomenika, reljefne motive i natpisnu građu da bi naglasili svoj socijalni status i društveni ugled? Jesu li na taj način implicirali da za njih ne vrijede ista pravila kao za druge članove unutar te društvene skupine, kako u ovozemaljskom, tako i u zagrobnom životu? Adekvatan odgovor odnosi se na prihvaćanje jedinstvene sepulkralne kulture svih kasnosrednjovjekovnih populacija, naru-

32 Š. BeŠLAGić, Stećci - kultura i umjetnost, str. 43.

33 Pitanjem podrijetla Vlaha bavili su se M. Wenzel, A. Benac, A. Milošević, D. Mandić, B. Hrabak, I. Mužić i dr. Veliki interes za izučavanje posljednjih godina pokazuje bosanskohercegovački povjesničar E. Kurtović. 
čivanje monolitnih nadgrobnih spomenika, njihovo pozicioniranje u prostoru i uporaba određenih simbola i motiva. Pri tome nije isključena teza da se dominantni status, kojega su uživali za života, nastojao projicirati i na zagrobni život. Međutim, ona nije uvijek potkrijepljena arheološkim istraživanjima i analizama grobnih cjelina, posebno jer se radi o malom broju analiza ljudskih zemnih ostataka što predstavlja jednu u nizu prepreka pri interpretiranju kulture pokapanja pod stećcima. Kontradiktorno navedenoj tezi jest brojno stanje stećaka te činjenica da ih je više od 5.000 (5.679) reljefno ukrašeno, a oko 300 (323) ih ima i natpise. S obzirom na brojnost stećaka i varijante oblika, u obzir treba uzeti hipotezu da su pod stećcima pokapani svi, a ne isključivo bogati sloj društva.

Stratifikacija unutar društvenoga poretka provjerljiva je fizičko-antropološkim i bioarheološkim analizama ljudskoga osteološkog materijala koje daju uvid u uvjete života, zdravstveno stanje ljudi i način prehrane. Relevantan pokazatelj bili bi raznolikost u grobnom materijalu i prilozima te varijacije građevina ili nastambi unutar naselja, no raspolažemo $s$ malim brojem podataka u svezi s naseljima i nastambama. Dobiveni bi rezultati svakako bili indikatori dostupnosti ekonomskih i prirodnih resursa.

Posljednjih su godina publicirane dvije monografije, Stećci, bosansko i humsko mramorje srednjeg vijeka povjesničara Dubravka Lovrenovića i nacionalna monografija Stećkopedija - kameno blago stare bosanske države Edina Bujaka. ${ }^{34}$ Monografija D. Lovrenovića posvećena je Šefiku Bešlagiću koji je svojim znanstvenim radom i zalaganjem postavio temelje za izučavanje stećaka. Autor je prezentirao najznačajnija dostignuća tijekom nešto više od jednog stoljeća izučavanja stećaka, koja su mu poslužila kao temelj za inkorporiranje stećaka u kontekst srednjovjekovne europske kulture. Pristupio je i povijesnom

34 Značaj Stećkopedije temelji se na uvažavanju relevantne povijesne i arheološke literature, rezultata arheoloških istraživanja i terenskoga rada autora. Predočenim rukopisom zaokružene su dosadašnje spoznaje o stećcima. Međutim, osobite vrijednosti ove publikacije su dostupnost i razumljivost koje će je učiniti prihvatljivom širokom krugu čitatelja. Na tomu tragu metodičkim strukturiranjem teme i koncepta autor sistematično uvodi recipijente u problematiku izučavanja stećaka, što će im omogućiti usvajanje bitnih značajki i kompleksnoga sadržaja motiva i epitafa na stećcima. Autor propituje i problem njihova očuvanja te implementiranja svih zakonskih i pravnih odredbi, kao i nedostatak arheoloških istraživanja samih grobova ispod stećaka. EDIN BUנAK, Stećkopedija - kameno blago stare bosanske države, Mladinska knjiga, Sarajevo, 2018. 
dekonstruiranju bogumilske teze o stećcima, te analizi ikonografskog opusa i epitafa na stećcima, stavljajući naglasak na njihovu interkonfesionalnost. ${ }^{35}$ Stećkopedija E. Bujaka u tehničkom smislu nadilazi do sada poznate publikacije. Korak po korak, čitatelj tekstualno i vizualno upoznaje svijet stećaka, značajke srednjovjekovne sepulkralne kulture kojom je obuhvaćen i značajan fundus arheološkoga materijala pronađenoga u grobovima. Autor je u publikaciji objavio posve nove rezultate arheoloških istraživanja i DNK analiza osteološkoga materijala s nekropola koje je istraživao posljednjih godina.

I uz veliki broj publikacija o stećcima čini se kako još uvijek nismo u mogućnosti ponuditi konkretnu sliku o sepulkralnoj kulturi srednjovjekovne Bosne i Huma. Razlog tomu svakako je nedostatak arheoloških istraživanja ali i teorijskih pristupa koji su zastupljeni u svjetskoj arheološkoj znanosti. Za razliku od ostatka Europe gdje se srednjovjekovna arheologija teorijski proučava samostalno, kasnosrednjovjekovna arheologija u Bosni i Hercegovini i Hrvatskoj nema jasno definiran teorijski okvir. ${ }^{36}$ Točnije, teorijska arheologija nije zastupljena u radovima i publikacijama vezanim za nekropole stećaka. U svom članku Medieval archaeology and theory: a disciplinary leap of faith $\mathrm{R}$. Gilchrist razmatra srednjovjekovnu arheologiju kroz razvoj tri dominantne arheološke perspektive. ${ }^{37}$ Pod utjecajem procesualizma srednjovjekovna se arheologija specijalizirala u temama koje su negirali konvencionalni pisani izvori, uključujući i istraživanje arheoloških krajolika. ${ }^{38} \mathrm{M}$. Johnson bavio se pitanjem srednjovjekovne arheologije krajolika, izražavajući stav kako su arheološka obilježja u krajoliku zabilježena objektivno te da su zbog toga dobila status stvari koje govore za sebe. M. Johnson i T. Ingold zago-

35 D. Lovrenović, Stećci, bosansko i humsko mramorje srednjeg vijeka.

$36 \mathrm{O}$ povijesnom razvoju arheologije kao humanističke znanosti u zemljama jugoistočne Europe (Slovenija, Hrvatska, Bosna i Hercegovina, Srbija, Makedonija, Crna Gora i Kosovo) pisao je Predrag Novaković. Vidi: Predrag Nova Ković, Historija arheologije u novim zemljama jugoistočne Europe, Univerzitet, Sarajevo, 2015.

37 Gilchrist navodi kako je britanski arheolog R. Hodges prvi pozvao srednjovjekovne arheologe na odbacivanje kulturno-povijesne paradigme, zagovarajući procesne pristupe utemeljene na teoriji sustava i modelu izgradnje, ističući važnost unutarnjih i vanjskih procesa u transformiranju društava, što je na svojevrstan način definiralo empirijski stav srednjovjekovne arheologije.

38 R. Gilchrist, "Medieval archaeology and theory: a disciplinary leap of faith", str. 385-386. 
varali su fenomenološke pristupe proučavanja krajolika. ${ }^{39}$ Koncepti prostora i krajolika na našim prostorima zastupljeni su u radovima Predraga Novakovića. ${ }^{40}$ U postojećoj literaturi o stećcima, proučavanje prostornoga rasporeda nekropola prepoznatljivo je u kontekstu ekonomsko-funkcionalnoga stajališta procesne arheologije, prema kojemu je nastanak nekropola bio uvjetovan bogatstvom kamena, tj. blizinom kamenoloma, konfiguracijom terena, tehnološkim mogućnostima kovača i dijaka, te udaljenostima naselja i nekropole. Međutim, nekropole stećaka moguće je sagledati u kontekstu arheologije prostora i krajolika, koje daju uvid ne samo u distribuciju nekropola i ekonomsko-funkcionalne parametre, nego proučavaju prostor kao humanizirani objekt. ${ }^{41}$ Pozicioniranje nekropola u prostoru i krajoliku, fizičku povezanost s komunikacijama i lokalitetima iz ranijih arheoloških razdoblja, te simboličku komponentu stećaka, autorica je razmatrala u svojoj doktorskoj disertaciji. ${ }^{42}$

Osim navedenih promjena važno je istaknuti kako 80 -ih godina dolazi do ponovnoga procvata marksizma u društvenim znanostima, stavljanjem naglaska na simboličku i ideološku funkciju predmeta (neomarksizam), te na ulogu ideologije u društvenim procesima. Marx koristi ideologiju kao sredstvo preko kojega vladajuće strukture održavaju svoju moć. ${ }^{43}$

Kad se proučavanje stećaka pokuša staviti u navedene kontekste, uviđa se kako epigrafska i reljefna građa imaju upravo neomarksističke elemente zastupljene u postprocesnom pristupu. Na prividno življenje viteške kulture i vjerne službe gospodaru, asocirali su motivi poput štita i mača, scena lova i mačevanja, te pojedini epitafi na nadgrobnim spomenicima. Nasuprot toj socijalno-društvenoj komponenti, postavljanjem solarno-lunarnih motiva i simbola križa u religijski kontekst naglašena je duhovna komponenta. Stoga je po-

39 Mathew Johnson, Ideas of landscape, Blackwell Publishing, 2007., str. 83-89, 117-119.

40 Predrag Novaković, Prostorska in pokrajinska arheologija: študija na primjeru Krasa, Doktorska disertacija, Ljubljana, 2001.; PREDRAG Novaković, "Arheologija prostora i arheologija krajolika", u: Povijest u kršu, Zbornik projekta "Naselja i komunikacije u kontekstu veza Jadranskog priobalja i unutrašnjosti u prapovijesti i antici", Zagreb, 2008.

41 P. Novaković, "Arheologija prostora i arheologija krajolika", str. 15.

42 http://darhiv.ffzg.unizg.hr/id/eprint/10760/1/Vucic_Edita.pdf (10. 2. 2019.).

43 R. Šošić-KLINDžıć, Uvod u teorijsku arheologiju - stvaraoci i pravci u XX. st., str. 125. 
trebno propitati egzistirajuće pretpostavke o postojanju predložaka i ustaljenih formi ukrašavanja nadgrobnih spomenika, njihovom stilskom oblikovanju, te interpretacijama u kontekstu kršćanske ikonografije ili života srednjovjekovne feudalne vlastele.

Značenjem simbola bavio se Ian Hodder koji smatra kako se "riječ simbol odnosi na objekt ili situaciju u kojoj direktno, primarno ili doslovno značenje također određuje indirektno, sekundarno i figurativno značenje". Hodder smatra da simboli imaju aktivnu ulogu u oblikovanju socijalnoga ponašanja. ${ }^{44}$

Terenska istraživanja koje je provela autorica ovoga rada rezultirala su spoznajama o brojnim kombinacijama motiva i simbola na stećcima, što ukazuje na to da se ne može govoriti o uniformiranosti ili kreiranju obrazaca po kojima će im se pripisivati određena značenja. U konačnici, mišljenja smo kako je došlo vrijeme za napuštanje "standarda"45 u istraživanju, kao i za razvoj metodologije koja će ujediniti više znanstvenih disciplina, te omogućiti širi spektar spoznaja o ikonografiji stećaka. Na to ukazuju dosadašnje interpretacije o utjecajima europskoga zapada, tj. romaničke i gotičke umjetnosti, ali i istovremena "degradacija" kvalitete izvedbe motiva rađenih u plitkom reljefu, promatrane kao arhaični lokalni izričaj. Poznavatelju ikonografskoga opusa na stećcima jasno je kako interpretiranje umjetničke vrijednosti stećaka može ići u više smjerova. Terenska su istraživanja pokazala da na stećcima nema didaktičko-teoloških sadržaja iz Biblije, te da se značenje određenoga motiva treba promatrati u interakciji sa sveukupnom likovnošću stećka, a stećak kao fizički objekt, apstraktni oblik ili kao nematerijalnu realnost. ${ }^{46}$

44 I. HodDer, Symbols in action - Etnoarchaeological studies in material culture, str. 11-12.

45 Pod standardima se podrazumijevaju interpretacije koje nalazimo u radovima eminentnih imena poput Š. Bešlagića, N. Miletić, A. Benca, M. Vege, Ć. Truhelke, M. Wenzel i brojnih drugih autora kojima svakako dugujemo veliku zahvalnost za sve podatke kojima danas raspolažemo. Čini se ipak kako se još uvijek nastoje "oživjeti" stare teze, te sukladno suvremenim konstruktima, staviti naglasak na vjerski i nacionalni identitet pokojnika, u obliku koji nije postojao u razdoblju srednjega vijeka. Doda li se toj konstataciji činjenica da raspolažemo s malim brojem fizičko-antropoloških i bioarheoloških analiza osteološkoga materijala, jasno je kako nije došlo do značajnoga pomaka u istraživanju podzemne dimenzije srednjovjekovnih nadgrobnih spomenika, te naseobina i načina života onovremenih populacija.

46 Gorčin Dizdar, Stećak, Vrijeme, Zenica, 2018., str. 84-87. 
Podsjetimo kako je identična tematika fascinirala prapovijesnoga čovjeka, koji je zidove spilja oslikavao geometrijskim i astralnim motivima, scenama lova na životinje, iskazujući na taj način svoj duhovni svijet, ali i svakodnevni život. Tisućljećima kasnije ti su motivi usvajani i prilagođavani potrebama čovjeka i vremena u kojemu je egzistirao. U istoj je mjeri srednjovjekovnom čovjeku vizualno bila dostupna rimska umjetnost, što se očituje u odabiru reljefnih motiva poznatih iz antičkoga razdoblja. Sve to upućuje na zaključak kako su stećci nastali kao rezultat prežitaka ranijih epoha i vjerovanja koja su nama još uvijek nepoznata. U konačnici, ne isključujući utjecaje europskih kultura i umjetnosti, kasnosrednjovjekovne su populacije uspjele pronaći osobni izričaj kojim su obilježile svoj egzistencijalni doživljaj, ujedno dajući novo značenje štovanju kulta predaka prapovijesnih i kasnijih arheoloških populacija. Pokapajući se na tumulima ili na lokalitetima s ukopima iz kasnijih arheoloških razdoblja, prostornom su razmještaju dali potpuno novu simboličku konotaciju. Na taj su se način nastojali identificirati sa svojim pretcima rekreirajući odnose prema njima, ali i svoje osobne identitete. Kasnosrednjovjekovna su groblja izražavala monumentalnost u formi stećka, baš kao i rimska u formi stele i mauzoleja ili prapovijesna $\mathrm{u}$ formi gomile. Upravo monumentalna izvedba nadgrobnih spomenika kao vječnih počivališta asocira na vrhunska arhitektonska ostvarenja europskoga srednjeg vijeka. To je jedna od malobrojnih poveznica koja stećke identificira s umjetničkim ostvarenjima europske gotike, iako u suvremenoj literaturi postoje analogije koje su, ukoliko ih se pomno analizira, nedovoljno argumentirane. Sljedeća poveznica između kasne gotičke umjetnosti i humanizma kojim se čovjeka stavlja u prvi plan, jesu prikazi ljudskih figura, polufigura ili samo ruke na stećcima. Upravo ta eshatološko-humanistička dimenzija, uz brojno stanje stećaka, ide u prilog konstataciji da je čovjek kasnoga srednjeg vijeka bio opčinjen smrću.

U pokušaju pronalaska adekvatnih interpretacija o okolnostima nastanka srednjovjekovne sepulkralne kulture, treba iskoristiti elemente i pozitivna iskustva povijesnoga razvoja sva tri navedena pristupa, oslanjajući se na nove znanstvene spoznaje, prilagođavajući ih potrebama suvremene epistemologije. Tri navedena teorijska pristupa zastupljena su u određenom razdoblju arheološke znanosti i neisključiva su, jer nijedan od njih nije funkcionalan u rješavanju arheološkoga problema ukoliko se izostave elementi druga dva. $\mathrm{Na}$ tragu ovakvih promišljanja dolazi se do spoznaje kako su prilikom odabira mjesta za svoja vječna počivališta te populacije uzimale u 
obzir ekonomsko-funkcionalnu komponentu, ali ona nije bila od presudne važnosti. Veliku su ulogu odigrali i prežitci ranijih epoha te uplivi europske kulture. Indikatori štovanja ranijih kultova ili pak reinterpretacije i prefiguracije njihove simbolike jesu astralni i solarno-lunarni motivi i simbol križa na stećcima, koji su ujedno i najzastupljeniji na stećcima, te pozicioniranje nekropola na određenim lokacijama u prostoru. Daljnje proučavanje pojavnosti nekropola stećaka zahtijeva inovativniji metodološki pristup koji će objediniti rezultate terenskih istraživanja i teorijske perspektive. U istraživanju se treba osloniti i na arheologiju prostora i krajolika, koje će zasigurno ponuditi više podataka o tomu kako je kasnosrednjovjekovni čovjek percipirao svijet oko sebe i zašto je vječna počivališta pozicionirao na određenim mjestima u prostoru. Na taj će se način nekropole stećaka sagledati kroz prizmu postprocesne arheologije koja iznosi stajalište kako logika smještaja lokaliteta, spomenika ili artefakta sadrži brojne kulturne elemente, ujedno se baveći načinom na koji čovjek percipira prostor oko sebe, te djeluje unutar njega. ${ }^{47}$ Zaključno, valoriziranje i proučavanje stećaka zahtijeva odbacivanje konvencionalnih paradigmi i stereotipa koji i danas kruže u znanstvenim krugovima, te kritički pristup u kojemu će istovremeno egzistirati dinamična mišljenja u skladu sa suvremenom epistemologijom.

47 IAn Hodder, The present past, Batsford, Cambridge University press, Cambridge, London, 1982. 
EDITA VuČIĆ

\section{Contextualization of stecak necropolises in theoretical archaeology}

\section{Summary}

The article seeks to raise awareness on the lack of theoretical perspectives in discourses related to studying stecaks. If we summarize previous studies of the stecak necropolises phenomenon, it is obvious that they are in the margins of the scientific disciplines such as archaeology, art history, history, linguistics, etc. Therefore it is necessary to give a critical opinion on some ingrained and in the science rooted "regularities". It is obvious that according to progress of the epistemological thought, studying of stecaks requires an interdisciplinary approach and significantly wider interpretative framework. Critical thinking could not be possible without the field research of the author of this article as well as review of theoretical perspectives in the world archaeological science. The same will be taken as the basis for new interpretations and attempt to incorporate stecaks in contemporary archaeological flows. The purpose of the research set in that way is to try to understand medieval sepulchral culture better and question the existing paradigms.

Keywords: stecak necropolises; course of the study; critical thinking; theoretical archaeology; new interpretations. 